\title{
Chilled Potatoes Decrease Postprandial Glucose, Insulin, and Glucose-dependent Insulinotropic Peptide Compared to Boiled Potatoes in Females with Elevated Fasting Glucose and Insulin
}

\author{
Mindy A Patterson ${ }^{1, *}$, Joy Nolte Fong ${ }^{1}$, Madhura Maiya ${ }^{1,2}$, Stephanie Kung ${ }^{1}$, Araz Sarkissian ${ }^{1}$, \\ Nezar Nashef ${ }^{1}$ and Wanyi Wang ${ }^{3}$ (i) \\ 1 Department of Nutrition and Food Services, Texas Woman's University, 6700 Fannin Street, \\ Houston, TX 77030, USA \\ 2 Office of Research and Sponsored Programs, Texas Woman's University, 6700 Fannin Street, \\ Houston, TX 77030, USA \\ 3 Center for Design and Research, Texas Woman's University, 6700 Fannin Street, Houston, TX 77030, USA \\ * Correspondence: mpatterson14@twu.edu or mindyannpatterson@outlook.com; Tel.: +1-713-794-2375
}

Received: 11 August 2019; Accepted: 30 August 2019; Published: 3 September 2019

\begin{abstract}
Resistant starch (RS) has been shown to improve postprandial glycemia and insulin sensitivity in adults with metabolic syndrome. RS is found naturally in potatoes, where the amount varies based on cooking method and serving temperature. Thirty females with a mean BMI of 32.8 $\pm 3.7 \mathrm{~kg} / \mathrm{m}^{2}$, fasting glucose of $110.5 \mathrm{mg} / \mathrm{dL}$, and insulin of $10.3 \mu \mathrm{IU} / \mathrm{L}$, completed this randomized, crossover study. A quantity of $250 \mathrm{~g}$ of boiled (low RS) and baked then chilled (high RS) russet potatoes were consumed on two separate occasions. Glycemic (glucose and insulin) and incretin response, subjective satiety, and dietary intake were measured. Results showed that the chilled potato elicited significant reductions at 15 and $30 \mathrm{~min}$ in glucose $(4.8 \%$ and $9.2 \%)$, insulin ( $25.8 \%$ and $22.6 \%)$, and glucose-dependent insulinotropic peptide (GIP) $(41.1 \%$ and $37.6 \%)$, respectively. The area under the curve for insulin and GIP were significantly lower after the chilled potato, but no differences were seen in glucose, glucagon-like peptide-1, and peptide $Y Y$, or overall subjective satiety. A higher carbohydrate and glycemic index but lower fat diet was consumed 48-hours following the chilled potato than the boiled potato. This study demonstrates that consuming chilled potatoes higher in RS can positively impact the glycemic response in females with elevated fasting glucose and insulin.
\end{abstract}

Keywords: glucose homeostasis; resistant starch; incretins; subjective satiety; dietary intake

\section{Introduction}

Innovative dietary modifications of commonly consumed foods are needed to combat the rising epidemic of prediabetes. Potatoes are a staple food commodity in many countries and are the third most consumed crop followed by rice and wheat in the United States [1]. Rich in complex carbohydrates, vitamins $\mathrm{C}$ and $\mathrm{B} 6$, potassium, magnesium, and fiber, while low in fat and sodium, potatoes provide essential nutrients that contribute to the recommended dietary needs of many individuals [2].

Starch is the primary carbohydrate found in potatoes and includes both digestible and nondigestible starch, or resistant starch (RS). Resistant starch cannot be broken down by digestive enzymes and enters the large intestine intact. Of the five types of RS, type 2 (RS2) is found in raw and cooked potatoes, while type 3 (RS3) is present in cooked, then chilled potatoes. Environment, natural selection, variety, storage conditions and duration, cooking method, and serving temperature influence the amount of RS in potatoes [3]. Boiled, baked, or microwaved potatoes contain less RS (mean $2.3 \mathrm{~g} / 100 \mathrm{~g}$ ) than cooked 
then chilled potatoes (mean $5.6 \mathrm{~g} / 100 \mathrm{~g}$ ) [4]. Heat and water allow the amylose and amylopectin in the starch granule to disassociate, allowing increased accessibility to digestive enzymes, but chilling reforms the amylose and amylopectin into a packed structure, a process known as retrogradation [5].

Resistant starch can influence health-related outcomes through several mechanisms, especially in individuals at risk for developing chronic diseases, including prediabetes. Both RS2 and RS3 can be fermented by gut microbes to produce metabolites such as short-chain fatty acids (SCFA; butyrate, propionate, and acetate), $\mathrm{CO}_{2}$, and methane [6]. The metabolites, specifically SCFA, can bind to fatty-acid receptors on the colonocytes to stimulate the release of incretins, such as glucagon-like peptide-1 (GLP-1) [7,8] and glucose-dependent insulinotropic-polypeptide (GIP) [9], as well as peptides known to influence satiety, such as peptide YY (PYY) [7,10]. Attenuated post-prandial glucose [11] and improvements in insulin sensitivity in adults with metabolic syndrome [12,13] have been observed in human trials following RS intake. However, these trials utilized 15-40 $\mathrm{g}$ of high-amylose maize RS2 as a functional ingredient or supplement over 4-8 weeks. Different types of RS have demonstrated improvements in satiety and subsequent energy. Improved satiety following RS4 [14], and reduced energy at a subsequent meal after RS2 [15], and over 24-hour following wheat RS [16] intake have been observed. Although these trials did not use RS3 as an intervention, significant reductions in glycemic response have been observed following acute cooked then chilled potato consumption, which would have higher concentrations of RS3 - although the amount was not reported-compared to boiled potatoes [17]. Currently, the use of RS3 as a daily intervention of longer duration ( $\geq 4$ weeks) in clinical trials examining glycemic and satiety outcomes is limited. Randomized-controlled feeding trials of longer duration using RS3 are needed to provide more evidence on the possible glycemic benefits of different types of RS.

Because potatoes are widely consumed worldwide and are a natural source of RS that can be altered by the cooking method and serving temperature, it is important to identify the potato form that most favorably modulates glycemic response to help combat the progression of chronic disease in overweight and obese adults. Thus, the purpose of this study is to compare glucose, insulin, incretin (GLP-1 and GIP), and a peptide known to influence satiety (PYY) concentrations following the intake of (1) boiled russet potatoes consumed hot and (2) baked then chilled russet potatoes consumed cold, in overweight and obese females with elevated fasting glucose and insulin concentrations. In addition, we examine the relationship among gut-derived peptides, subjective satiety, and 48-hour subsequent energy and nutrient intake following boiled and chilled potato consumption, as well as how body composition may influence glycemic response. We hypothesized that glycemic response would be attenuated following chilled potato intake, which may be augmented by incretin secretion. We also hypothesized that subjective satiety would be higher and 48-hour subsequent energy would be lower following intake of the chilled potato compared to intake of the boiled potato. The rationale behind a reduction in subsequent energy is related to the delayed fermentation of RS which has been shown to occur between 5 to $7 \mathrm{~h}$ following intake [18]. The metabolites produced from RS fermentation by the gut microbiota would stimulate the production of incretins and satiety peptides to influence subsequent energy.

\section{Material and Methods}

\subsection{Study Design}

Thirty premenopausal overweight and obese females (BMI $\geq 28-40 \mathrm{~kg} / \mathrm{m}^{2}$ ) between 18 and 45 years of age of any ethnicity and race were enrolled in this randomized crossover study. Exclusion criteria included a diagnosis of diabetes or other metabolic disorder, cancer, or cardiovascular disease. Although the inclusion criteria for prediabetic concentrations of fasting glucose and insulin were not a component of the screening procedures, the study results indicated the females had elevated fasting glucose and insulin at baseline. Additional exclusion criteria included nicotine or drug use, females who were pregnant or lactating, and those presenting a significant weight change ( $\geq 5 \%$ over the prior 
six months) or following a special diet (e.g., gluten-free, low carbohydrate). Subjects with a sensitivity or aversion to potatoes were excluded. The subjects were recruited from the Texas Medical Center in Houston, Texas, and surrounding areas.

Subjects were randomized based on a random number generator to receive one of the following on the first visit: $250 \mathrm{~g}$ boiled russet potato consumed hot or $250 \mathrm{~g}$ baked then chilled russet potato consumed chilled. Body composition (fat and fat-free mass) was assessed using air displacement plethysmography (BOD POD ${ }^{\circledR}$, COSMED USA Inc., Concord, CA, USA) with the subject wearing spandex clothing and a swim cap at the first visit only. Subjects arrived fasted for $\geq 8 \mathrm{~h}$ other than water at the study center on two separate occasions with a minimum of one-week wash-out between visits. Following fasting blood collection, the subjects were given either the boiled or chilled potato based on randomization. A research assistant noted the start and finish time, based on a timer associated with each subject. The subjects consumed their potato within $15 \mathrm{~min}$ with $237 \mathrm{~mL}$ of water. Additional blood was collected at 15, 30, 60, and $120 \mathrm{~min}$ at the completion of potato intake. A $100 \mathrm{~mm}$ visual analogue scale (VAS) [19] assessed subjective satiety at 15 and $60 \mathrm{~min}$ after the intake of each potato. All timed measurements were logged on the data collection sheet. Food records were completed three days prior to and $48 \mathrm{~h}$ following each potato intervention for a total of ten records per subject. The day prior to each intervention, the subject was instructed by a Registered Dietitian Nutritionist to consume a low-fiber $(\leq 10 \mathrm{~g})$ diet. This study was approved by the University Institutional Review Board in Houston, Texas, and all subjects provided informed consent prior to data collection. The trial was registered with the U.S. National Library of Medicine (NCT Clinical trial number NCT0331047).

\subsection{Potato Preparation}

Russet potatoes of similar size were purchased from the same local grocery store prior to each intervention. The boiled potatoes were prepared by washing, peeling the skin, dicing into $2.54 \mathrm{~cm}$ cubes, and boiled in water for $15 \mathrm{~min}$ until soft. The decision to peel the potato prior to boiling, as well as the duration of boiling time, was to mimic typical preparation methods used when boiling potatoes. The potatoes were drained, measured to the nearest gram, and served to the subject while hot without any additives. The chilled potatoes were washed and wrapped in foil, then baked in a convection oven at $218^{\circ} \mathrm{C}$ for $90 \mathrm{~min}$ or until soft. The foil was removed, and the potato was placed in a sealed container and stored at $4{ }^{\circ} \mathrm{C}$ for five days. The peeling remained on the potato during the baking and chilling process to preserve potato quality, which could have been reduced if the peeling were removed. The potatoes were chilled five days to maximize RS3 formation, which is similar to a protocol used previously [20] where potatoes were chilled for six days. However, due to food safety concerns, the potatoes were chilled five days. Immediately prior to consumption, the skin was removed, the potato was slightly mashed and weighed to the nearest gram, then served to the subject cold without any additives.

\subsection{Biomarker Analysis}

Blood was collected in EDTA (for glucose, insulin, and GIP measurements) and BD P800 (for GLP-1 and PYY measurements) vacutainers, centrifuged at $4000 \mathrm{rpm}$ for $15 \mathrm{~min}$ to separate plasma from erythrocytes. Plasma was aliquoted into $1.5 \mathrm{~mL}$ cryovials and stored at $-80^{\circ} \mathrm{C}$ until analyzed by a multi-mode reader (Synergy HI, BioTek ${ }^{\circledR}$ Instruments, Inc., Winooski, Vermont, U.S.A.). Glucose was determined by colorimetric analysis. Insulin, GLP-1(active), GIP (total), and PYY (1-36 and 3-36) were measured using an enzyme-linked immunosorbent assay from commercially prepared kits (Alpco, Salem, New Hampshire, U.S.A.) according to instructions. Calculated intra- and inter-coefficients of variation for all biomarkers were less than $10 \%$ and $15 \%$, respectively.

\subsection{Statistical Analysis}

The main outcome was to compare the area under the curve $\left(\mathrm{AUC}_{(0-120 \mathrm{~min})}\right)$ glucose between potato interventions (boiled vs. chilled). Based on previous data [10], a large effect size of 0.8 was 
calculated based on the significant reduction in AUC glucose observed after RS intake. For a more rigorous study design, a more conservative moderate-high effect size of 0.7 was used to calculate the sample size for this study. A priori analysis using $\mathrm{G} \times$ Power 3.1.9 determined a sample size of 29 for a paired- $t$ test with a power of 0.95 and alpha of 0.05 . The final sample size for this study included 30 subjects. Missing data were treated by pairwise deletion. Descriptive statistics (minimum, maximum, mean, and SD) were calculated for all continuous variables. The $\mathrm{AUC}_{(0-120 \mathrm{~min})}$ was calculated for each biomarker using the trapezoid formula. Differences between boiled and chilled potatoes at each blood collection time point and the $\mathrm{AUC}_{(0-120 \mathrm{~min})}$ was determined by a Wilcoxon signed ranks test. For the dietary data, the mean energy and nutrient intake three days prior to each intervention and subsequent $48 \mathrm{~h}$ were calculated for each potato intervention. The mean intake between each phase, as well as difference from pre-to-post was compared by Wilcoxon signed ranked test. The relationship among body composition and $\mathrm{AUC}_{(0-120 \mathrm{~min})}$ biomarkers, subjective satiety within-and-between potato interventions, and subjective satiety with the $\mathrm{AUC}_{(0-120 \mathrm{~min})}$ for biomarkers known to influence satiety were assessed using Spearman's rho correlations. SPSS version 25 (Armonk, NY, U.S.A.) was used to perform all analysis. A $p<0.05$ indicates a significant difference.

\section{Results}

\subsection{Subjects}

Data on subject recruitment, enrollment, completion, and analysis can be found in Figure 1. Of the potential subjects expressing interest $(n=111), 68.4 \%$ completed screening. Thirty-five subjects met inclusion criteria, with $85.7 \%(n=30)$ completing the trial. Subject characteristics at baseline can be found in Table 1.

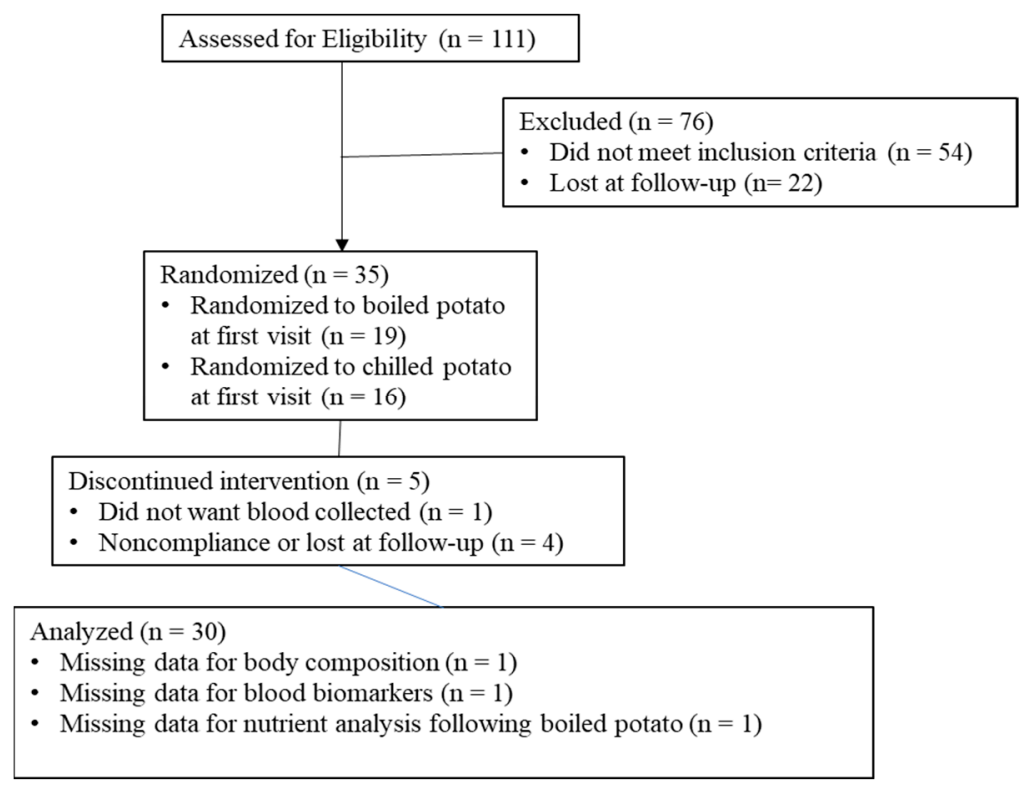

Figure 1. Subject flow through the study protocol. 
Table 1. Subject characteristics $(n=30)$.

\begin{tabular}{lc}
\hline \multicolumn{1}{c}{ Variables } & Mean \pm Standard Deviation $(\mathrm{SD})$ \\
\hline Age (years) & $29.6 \pm 6.0$ \\
\hline Body weight $(\mathrm{kg})$ & $85.6 \pm 11.8$ \\
\hline BMI $\left(\mathrm{kg} / \mathrm{m}^{2}\right)$ & $32.8 \pm 3.7$ \\
\hline Percent fat mass & $43.6 \pm 4.9$ \\
\hline Percent fat-free mass & $56.4 \pm 4.9$ \\
\hline Fat mass $(\mathrm{kg})$ & $37.9 \pm 8.0$ \\
\hline Lean mass $(\mathrm{kg})$ & $48.5 \pm 5.1$ \\
\hline
\end{tabular}

\subsection{Biomarker Response between Groups}

On average, our subjects had elevated fasting glucose of $110.5 \mathrm{mg} / \mathrm{dL}$ (normal values are $<100 \mathrm{mg} / \mathrm{dL}$ ) and fasting insulin of $10.3 \mu \mathrm{IU} / \mathrm{L}$ (normal values are $3-8 \mu \mathrm{IU} / \mathrm{mL}$ ) at baseline. No differences were observed in fasting biomarker concentrations between potato interventions. Glucose, insulin, GLP-1, PYY, and GIP postprandial responses at 15, 30, 60, and 120 min between each potato method are shown in Figure 2. Although the $\mathrm{AUC}_{(0-120 \mathrm{~min})}$ for glucose did not differ between boiled and chilled potatoes, which was the main outcome, glucose was lower at postprandial times of 15 and 30 min by $4.8 \%(p=0.03)$ and $9.2 \%(p=0.03)$, respectively, after consuming the chilled potato compared to the boiled potato. Insulin also decreased by $25.8 \%(p=0.005)$ at $15 \mathrm{~min}$ and $22.6 \%(p=0.004)$ at 30 min after intake of the chilled potato compared to the boiled potato. In addition, GIP was significantly lower at $15,30,60$, and $120 \mathrm{~min}$ by $41.1 \%, 37.6 \%, 36.4 \%$, and $23.5 \%$, respectively, following chilled potato intake compared to GIP after the boiled potato (all time points $p<0.0001$ ). No difference was observed for GLP-1 and PYY at any postprandial time point.
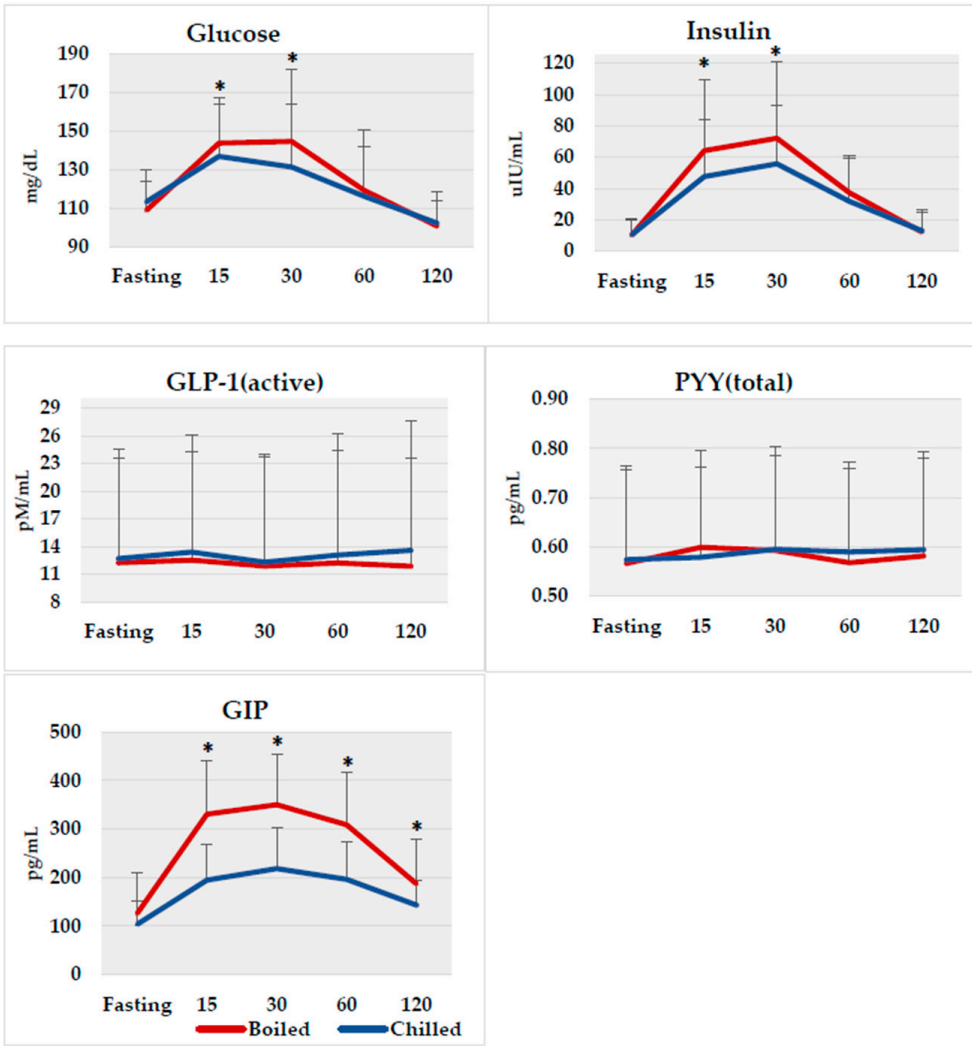

Figure 2. Biomarker responses from fasting to $120 \mathrm{~min}$ following boiled (red line) and chilled (blue line) potato intake. ${ }^{*} p<0.05$ between groups using non-parametric Wilcoxon Signed Ranks Test. GLP-1, glucagon-like peptide-1; PYY, peptide YY; GIP, glucose-dependent insulinotropic-peptide. 
The $\mathrm{AUC}_{(0-120 \mathrm{~min})}$ values for each biomarker were compared between potato methods and are displayed in Figure 3. Following chilled potato consumption, the $\mathrm{AUC}_{(0-120 \mathrm{~min})}$ for insulin and GIP were significantly lower by $17.7 \%$ and $35.1 \%$, respectively, compared to those following boiled potato consumption. No difference in the $\mathrm{AUC}_{(0-120 \mathrm{~min})}$ for glucose, GLP-1, or PYY occurred between groups.
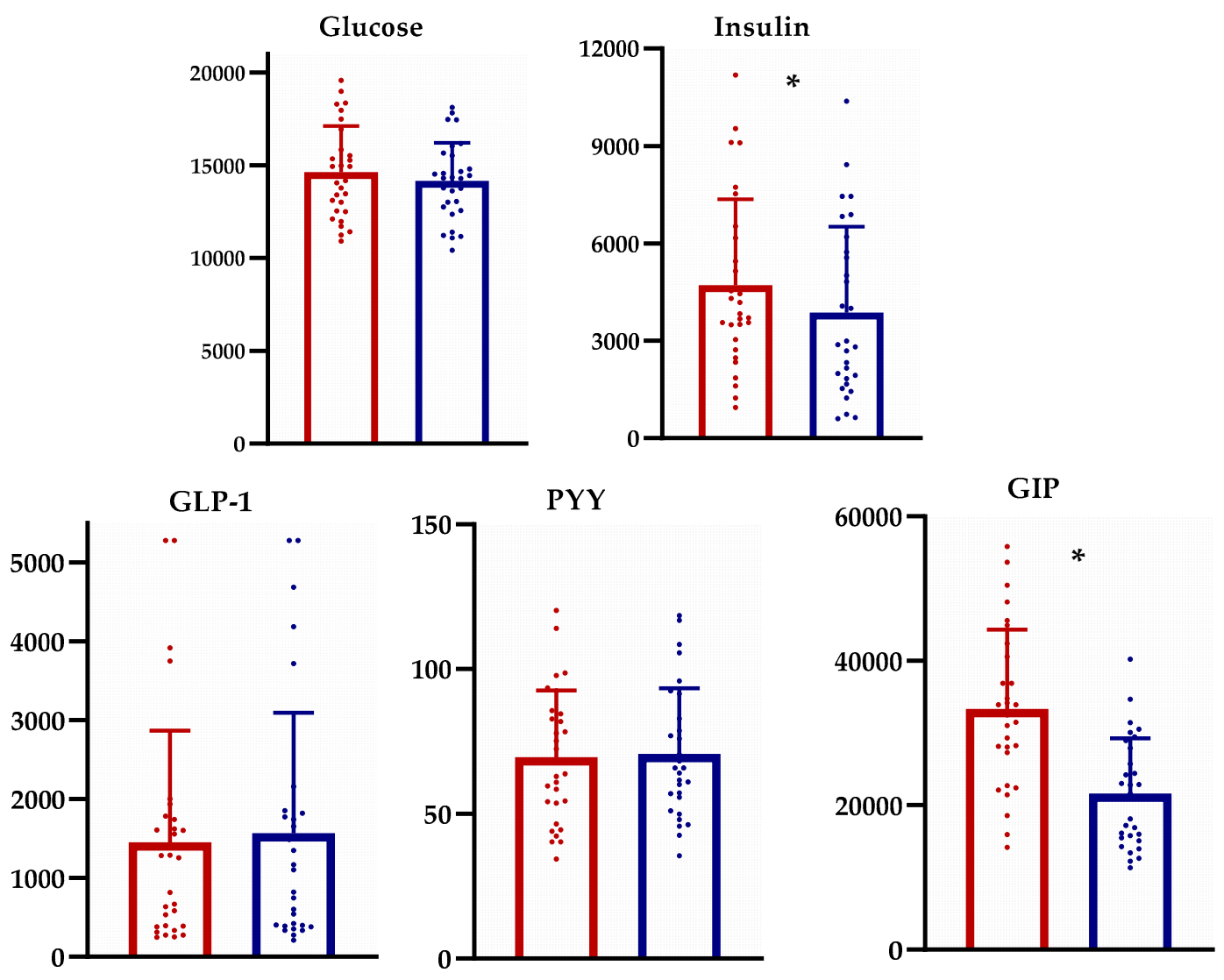

Figure 3. Comparison of the area under the curve $\left(\mathrm{AUC}_{0-120 \mathrm{~min}}\right)$ biomarker response between boiled and chilled potato intake. ${ }^{*} p<0.05$ between groups using non-parametric Wilcoxon Signed Ranks Test. Red color refers to the $\mathrm{AUC}_{(0-120 \mathrm{~min})}$ for the boiled potato; blue color refers to the $\mathrm{AUC}_{(0-120 \mathrm{~min})}$ for the chilled potato. GLP-1, glucagon-like peptide-1; PYY, peptide YY; GIP, glucose-dependent insulinotropic-peptide.

\subsection{Relationship among Body Composition and Biomarker Response between Interventions}

The subjects had a mean BMI of $32.8 \pm 3.7 \mathrm{~kg} / \mathrm{m}^{2}$. Because body composition can influence biomarker response to food, [21] the relationship between body composition and the $\mathrm{AUC}_{(0-120 \mathrm{~min})}$ for each biomarker was determined (Table S1). Percent fat mass $(r=0.425 ; p=0.024)$ was weakly positively correlated and fat mass in $\mathrm{kg}(r=0.387 ; p=0.042)$ was moderately positively correlated with insulin $\mathrm{AUC}_{(0-120 \mathrm{~min})}$ following chilled potato intake. Percent fat-free mass $(r=-0.425 ; p=0.024)$ showed a moderate negative association with insulin $\mathrm{AUC}_{(0-120 \mathrm{~min})}$ after chilled potato intake. These relationships were not found following boiled potato intake. In addition, fat-free mass in $\mathrm{kg}(r=-0.415$; $p=0.028)$ was moderately negatively associated with GIP $\mathrm{AUC}_{(0-120 \mathrm{~min})}$ following chilled potato intake. However, the correlation coefficient $(r)$ between the two groups was not significantly different; all $p>0.05$.

\subsection{Dietary Intake Before and after each Intervention}

Mean \pm standard deviation (SD) in dietary intake was recorded three days prior to and 48-hours following each potato intervention. The comparison of energy and nutrient intake before and after each potato, as well as the difference in change (pre-to-post), can be found in Table 2. No difference in dietary 
intake was observed before and after boiled potato intake. However, the percentage of kcal from carbohydrates and the intake of foods with a higher glycemic index increased while dietary saturated fat and percentage of kcal from fat decreased following chilled potato intake. When comparing the differences before and after each potato intervention, total, polyunsaturated, and saturated fat intake was less but the percentage of kcal from carbohydrates and foods with a higher glycemic index were increased following chilled potato intake compared to the boiled potato.

Table 2. Comparison of mean nutrient intake before and after each potato intervention.

\begin{tabular}{|c|c|c|c|c|c|}
\hline Variable & $\begin{array}{l}\text { Mean } \pm \text { SD } \\
\text { Boiled }\end{array}$ & $\begin{array}{l}p \text {-Value } \\
\text { Boiled }\end{array}$ & $\begin{array}{l}\text { Mean } \pm \text { SD } \\
\text { Chilled }\end{array}$ & $\begin{array}{l}p \text {-Value } \\
\text { Chilled }\end{array}$ & $\begin{array}{c}p \text {-Value } \\
\text { Difference in Change between Groups }\end{array}$ \\
\hline \multicolumn{6}{|l|}{ Energy (kcal) } \\
\hline Pre & $1828 \pm 842$ & 0.329 & $1933 \pm 891$ & 0.528 & \\
\hline Post & $1987 \pm 1223$ & & $1843 \pm 1220$ & & \\
\hline Difference & $160 \pm 865$ & & $-67 \pm 774$ & & 0.185 \\
\hline \multicolumn{6}{|l|}{$\mathrm{CHO}(\mathrm{g})$} \\
\hline Pre & $211.2 \pm 95.9$ & 0.55 & $206.0 \pm 83.8$ & 0.457 & \\
\hline Post & $223.9 \pm 140.6$ & & $218.6 \pm 130.3$ & & \\
\hline Difference & $12.7 \pm 112.7$ & & $16.1 \pm 90.8$ & & 0.876 \\
\hline \multicolumn{6}{|l|}{ Protein (g) } \\
\hline Pre & $76.6 \pm 45.2$ & 0.753 & $77.7 \pm 34.7$ & 0.895 & \\
\hline Post & $78.5 \pm 49.5$ & & $76.8 \pm 52.8$ & & \\
\hline Difference & $1.9 \pm 32.0$ & & $-1.2 \pm 37.2$ & & 0.72 \\
\hline \multicolumn{6}{|l|}{ Fat (g) } \\
\hline Pre & $76.6 \pm 40.5$ & 0.328 & $89.5 \pm 55.6$ & 0.065 & \\
\hline Post & $84.5 \pm 60.4$ & & $75.1 \pm 62.2$ & & \\
\hline Difference & $7.9 \pm 42.8$ & & $-13.2 \pm 41.4$ & & 0.026 \\
\hline \multicolumn{6}{|c|}{ Monounsaturated fat (g) } \\
\hline Pre & $27.7 \pm 15.7$ & 0.608 & $31.9 \pm 18.6$ & 0.095 & \\
\hline Post & $28.9 \pm 19.0$ & & $26.9 \pm 22.7$ & & \\
\hline Difference & $1.2 \pm 12.9$ & & $-4.5 \pm 16.0$ & & 0.09 \\
\hline \multicolumn{6}{|c|}{ Polyunsaturated fat (g) } \\
\hline Pre & $17.6 \pm 9.7$ & 0.294 & $22.0 \pm 15.0$ & 0.11 & \\
\hline Post & $20.2 \pm 16.7$ & & $18.1 \pm 14.2$ & & \\
\hline Difference & $2.6 \pm 13.3$ & & $-3.9 \pm 13.4$ & & 0.013 \\
\hline \multicolumn{6}{|l|}{ Saturated fat (g) } \\
\hline Pre & $24.8 \pm 13.6$ & 0.303 & $28.5 \pm 20.6$ & 0.047 & \\
\hline Post & $28.2 \pm 21.2$ & & $23.7 \pm 21.6$ & & \\
\hline Difference & $3.4 \pm 17.6$ & & $-4.2 \pm 12.5$ & & 0.045 \\
\hline \multicolumn{6}{|c|}{ Trans fatty acids (g) } \\
\hline Pre & $2.3 \pm 1.8$ & 0.679 & $2.4 \pm 1.6$ & 0.608 & \\
\hline Post & $2.2 \pm 1.3$ & & $2.6 \pm 2.9$ & & \\
\hline Difference & $-0.1 \pm 1.6$ & & $0.3 \pm 2.7$ & & 0.345 \\
\hline \multicolumn{6}{|l|}{$\%$ kcal from $\mathrm{CHO}$} \\
\hline Pre & $46.4 \pm 9.3$ & 0.488 & $44.0 \pm 8.7$ & 0.033 & \\
\hline Post & $45.3 \pm 10.7$ & & $49.3 \pm 11.7$ & & \\
\hline Difference & $-1.1 \pm 8.7$ & & $5.4 \pm 13.0$ & & 0.032 \\
\hline \multicolumn{6}{|c|}{$\%$ kcal from protein } \\
\hline Pre & $16.6 \pm 5.1$ & 0.875 & $16.8 \pm 4.6$ & 0.688 & \\
\hline Post & $16.4 \pm 4.6$ & & $16.4 \pm 5.3$ & & \\
\hline Difference & $-0.2 \pm 5.6$ & & $-0.7 \pm 5.4$ & & 0.692 \\
\hline \multicolumn{6}{|l|}{$\%$ kcal from fat } \\
\hline Pre & $36.5 \pm 6.6$ & 0.798 & $38.3 \pm 6.8$ & 0.032 & \\
\hline Post & $36.2 \pm 8.7$ & & $33.9 \pm 9.1$ & & \\
\hline Difference & $-0.4 \pm 7.6$ & & $-4.3 \pm 11.0$ & & 0.088 \\
\hline \multicolumn{6}{|l|}{ Fiber (g) } \\
\hline Pre & $14.8 \pm 7.0$ & 0.502 & $15.6 \pm 6.2$ & 0.418 & \\
\hline Pro & $15.8 \pm 10.2$ & & $16.7 \pm 8.9$ & & \\
\hline Difference & $1.1 \pm 8.3$ & & $1.5 \pm 7.0$ & & 0.813 \\
\hline
\end{tabular}


Table 2. Cont.

\begin{tabular}{lccccc}
\hline Variable & $\begin{array}{c}\text { Mean } \pm \text { SD } \\
\text { Boiled }\end{array}$ & $\begin{array}{c}p \text {-Value } \\
\text { Boiled }\end{array}$ & $\begin{array}{c}\text { Mean } \pm \text { SD } \\
\text { Chilled }\end{array}$ & $\begin{array}{c}p \text {-Value } \\
\text { Chilled }\end{array}$ & $\begin{array}{c}p \text {-Value } \\
\text { Difference in Change between Groups }\end{array}$ \\
\hline Glycemic index & & & & & \\
\hline Pre & & & $60.2 \pm 4.0$ & $\mathbf{0 . 0 0 1}$ & \\
Post & $59.8 \pm 4.5$ & 0.833 & $64.3 \pm 7.3$ & & $\mathbf{0 . 0 4 9}$ \\
Difference & $60.0 \pm 3.7$ & & $4.1 \pm 6.5$ & & \\
\hline Glycemic load & $0.2 \pm 5.9$ & & & & 0.171 \\
\hline Pre & & & $115.5 \pm 49.0$ & \\
Post & $118.2 \pm 52.8$ & 0.539 & $130.0 \pm 76.9$ & & \\
Difference & $125.1 \pm 78.3$ & & $15.3 \pm 52.6$ & & \\
\hline
\end{tabular}

* Glycemic index was calculated using glucose as the reference. The bold shows the significant differences.

\subsection{Subjective Satiety}

Data for subjective satiety, which includes the individual questions and how the scores were interpreted to measure subjective satiety, can be found in Table S2. When comparing each VAS question between time points within each group, the subjects had a $10.9 \mathrm{~mm}$ increase in mean score for "How hungry do you feel?" ( $p=0.026)$ and $13.6 \mathrm{~mm}$ increase in mean score for "How much do you think you can eat?" ( $p=0.012$ ) from $15 \mathrm{~min}$ to $60 \mathrm{~min}$ following consumption of the chilled potato. Based on the results of these two questions, the subjects had increased hunger from 15 to $60 \mathrm{~min}$ after chilled potato intake. Following intake of the boiled potato, the subjects scored $9 \mathrm{~mm}(p=0.028)$ higher for "How pleasant would you find eating another mouthful of this food?" at $60 \mathrm{~min}$ compared to $15 \mathrm{~min}$, suggesting they would find eating another bite pleasant.

When comparing VAS questions between potato interventions, the question "How pleasant would you find eating another mouthful of this food?" scored $10.7 \mathrm{~mm}$ higher $(p=0.028)$ after the boiled potato at $60 \mathrm{~min}$ postprandial than the chilled potato. These results indicate the chilled potato was less palatable than the boiled potato $60 \mathrm{~min}$ after consumption.

When comparing the gut-derived biomarkers to subjective satiety (Table S3), the $\mathrm{AUC}_{(0-120 \mathrm{~min})}$ GLP-1 was positively related $(r=0.369, p=0.049)$ to the mean score for "Would you like to eat something savory?" at $60 \mathrm{~min}$ following consumption of the boiled potato. No other gut-derived biomarkers were related to subjective satiety scores, which is an expected finding because the fermentation of RS is not likely to occur during this time frame.

\section{Discussion}

This study examined the impact of RS from russet potatoes on glucose metabolism, incretin secretion, and dietary intake in females with elevated fasting glucose and insulin. This study is novel in that it compared how cooking and serving methods modified RS amount from a natural, commonly consumed food on glycemic response. Although the $\mathrm{AUC}_{(0-120 \mathrm{~min})}$ glucose did not differ between groups, which was the primary outcome, the chilled potato reduced mean glucose and insulin in the immediate (15 and $30 \mathrm{~min}$ ) postprandial period, as well as the $\mathrm{AUC}_{(0-120 \mathrm{~min})}$ for insulin.

Similar to our findings, Ma et al. [22] found, in obese adults, a significant reduction in serum glucose $30 \mathrm{~min}$ following the consumption of $30 \mathrm{~g}$ RS from a muffin when compared to a glucose solution with equivalent digestible carbohydrate. Another study also examined glycemic and insulinemic responses in healthy adults following $40 \mathrm{~g}$ native banana starch beverage containing $28.2 \mathrm{~g}$ RS2 versus a $40 \mathrm{~g}$ digestible corn starch beverage, noting a significant reduction in glucose between 30 and $120 \mathrm{~min}$ and insulin between 60 and 90 min following the banana starch [23]. This study matched the total amount of beverage administered, not digestible carbohydrate, which is similar to the present study where the amount of potato $(250 \mathrm{~g})$ consumed was matched. Another study found a reduction in glucose at 15, 45, and $60 \mathrm{~min}$ following the intake of cooked rice that was cooled for $10 \mathrm{~h}$ compared to cooked rice in healthy adults [24]. The rice would have contained RS3 due to retrogradation of the starch granule from the cooling process, which is the type of RS found in the chilled potatoes 
in our study. Another study examining the glycemic index among potatoes matched for available carbohydrate found a reduction in the AUC glucose, which was not observed in the present study. Fernandes et al. [25] found that boiled red potatoes chilled between 12 and $24 \mathrm{~h}$ produced a larger reduction in the AUC glucose $(135 \mathrm{mmol} \mathrm{x} \mathrm{min} / \mathrm{L})$ than boiled red potatoes consumed hot $(208 \mathrm{mmol} \mathrm{x}$ $\mathrm{min} / \mathrm{L}$ ) [25]. However, a different type of potato was used, both males and females were included, the subjects had a lower mean BMI $\left(22.3 \mathrm{~kg} / \mathrm{m}^{2}\right)$, and the duration of the potato chilling process differed from the present study. These differences in study design may partially explain why a reduction in the $\mathrm{AUC}_{(0-120 \mathrm{~min})}$ following chilled potato intake did not differ from the values associated with boiled potato intake in the present study.

In the present study, the reduction in postprandial glucose at 15 and 30 min and the $\mathrm{AUC}_{(0-120 \mathrm{~min})}$ insulin following chilled potato intake may be partially explained by GIP secretion, which was also lower at all postprandial time points, and the $\mathrm{AUC}_{(0-120 \mathrm{~min})}$ following chilled potato intake. Glucose stimulates GIP release, which peaks within 5 min of glucose intake compared to GLP-1 release that peaks at $30 \mathrm{~min}$ [26]. Both GIP and GLP-1 have insulinotropic effects on pancreatic $\beta$-cells but are secreted in different sections in the gastrointestinal (GI) tract: GIP from the duodenum and GLP-1 from the distal ileum and colon $[27,28]$. The chilled potato contains more RS, which displaces the amount of available carbohydrate when compared to the boiled potato. Thus, less glucose is available, which was observed after the chilled potato at 15 and $30 \mathrm{~min}$ postprandially, to stimulate GIP in early digestion. The differences in the available carbohydrate between potatoes, not the production of SCFA from the fermentation of RS in the distal GI, is likely attributed to these results -especially, since GLP-1 concentrations were not different between potatoes. However, in mice, RS reduced GIP mRNA in the jejunum in a dose-dependent manner [28]. Other studies have found similar results to the present study regarding incretins, peptides that induce satiety, and VAS-measured subjective satiety [19]; but some studies have reported improvements in GLP-1 following RS intake [29]. Similar to GLP-1, no difference in PYY concentrations occurred between groups.

Interestingly, a higher insulin response was associated with the subjects who had a higher fat mass but lower fat-free mass following intake of the chilled potato but not the boiled potato (Table S1). This phenomenon may be due to metabolic inflexibility, where the subjects with a less favorable body composition were not able to physiologically adapt following the intake of the potato with less available carbohydrate [30]. Going from a fasted to fed state, or insulin-stimulating state, in a metabolic inflexibly environment contributes to insulin resistance by reducing glucose oxidation [31]. Skeletal muscle, which constitutes the majority of fat-free mass, plays a role in metabolic flexibility in that it accounts for $60-80 \%$ of glucose uptake as a result of insulin stimulation [32]. In our subjects, those with less fat-free mass demonstrated higher insulin concentrations when less carbohydrate was available, signifying a reduction in glucose oxidation.

Despite differences in RS between the boiled and chilled potatoes, an increase in subjective hunger was reported from 15 to $60 \mathrm{~min}$ following the chilled potato only. This result would not be related to the fermentation of RS to produce SCFA to stimulate the release of gut peptides GLP-1 and PYY that could induce immediate postprandial satiety. The fermentation of RS depends on gut transit time [33], which typically occurs between 5 and $7 \mathrm{~h}$ following RS intake [18], and would, therefore, not be captured within the $2 \mathrm{~h}$ window of subjective satiety measurement. Instead, the increased subjective hunger may be related to palatability. The subjects reported the chilled potato to be less pleasing or palatable from 15 to $60 \mathrm{~min}$ following consumption, which remained lower than the boiled potato at $60 \mathrm{~min}$. Obese individuals have shown higher hedonic hunger scores compared to non-obese individuals, which are inversely associated with glycemic control [34]. Owing to a combination of the reduction in palatability and lower insulin levels, the chilled potato may have caused an increased perception of hunger with a decreased stimulus from insulin in the reward center of the brain [35]. Additionally, a higher dose of RS may be needed to see a significant change in subjective satiety scores [29]. The type of RS may also impact satiety, where one study found RS3 supplement had lower satiety scores than an RS2 supplement [36]. 
Following the chilled potato intervention, an increased percentage of energy from carbohydrates and higher glycemic foods were consumed when compared to intake prior to the intervention, as well as the change from pre-to-post following the boiled potato. The carbohydrate foods displaced dietary fat while energy stayed the same. The lower amount of available carbohydrate consumed with the chilled potato could have promoted an increase in carbohydrate-rich foods. According to a review of RS on energy intake and subsequent, subjective satiety in healthy subjects [37], the majority of studies found no differences in VAS scores and mixed results for total energy intake following RS consumption [35-40].

The present study has several strengths. A commonly consumed, natural food product was used for the intervention. The amount of potato administered was approximately 8 ounces, or 1 cup, which is an amount that could be consumed in one meal. In addition, a realistic dose of RS found naturally in potatoes was used in the intervention, whereas most clinical trials use much higher doses of RS ( 15-40 g/day) as a supplement in the intervention. The randomized, crossover study design allowed for a sufficient sample $(n=30)$, while minimizing the confounding variables. The present study also analyzed dietary intake over a 10-day period ( 3 days prior to and $48 \mathrm{~h}$ following each intervention) to include weekdays and weekends that most likely represented habitual eating patterns.

Several limitations should also be noted. The study was not blinded due to the differences in potato intervention (chilled vs. hot). Only females were included, so the findings cannot be extrapolated to other populations and disease states. Also, although the potatoes were purchased from the same local grocery store, growing and storage conditions were not controlled which could impact RS concentration [3].

\section{Conclusions}

Chilled potatoes with a higher concentration of RS, thus less available carbohydrate, are effective in reducing postprandial glucose, insulin, and GIP, when compared to boiled potatoes consumed hot. A less favorable body composition resulted in a less favorable insulinemic response after chilled potato intake. The chilled potato did not induce satiety, it was less palatable, and it did not alter subsequent energy intake when compared to the boiled potato. Altering the cooking method and serving temperature of this staple food has the potential to improve glycemic indices in females with elevated fasting glucose and insulin.

Supplementary Materials: The following are available online at http://www.mdpi.com/2072-6643/11/9/2066/s1, Table S1: Correlations among body composition and the area under the curve (AUC) for biomarker responses following boiled and chilled potato intake ${ }^{1,2}$, Table S2: Comparison of within-and-between group mean subjective satiety scores measured at 15 and $60 \mathrm{~min}$ following boiled and chilled potato intake, Table S3: Correlations between the area under the curve for biomarkers known to influence satiety and mean subjective satiety scores between potato interventions ${ }^{1,2}$.

Author Contributions: M.A.P. designed the study and received funding for the study. M.A.P. and W.W. performed the statistical analysis and interpreted the results. M.A.P. and J.N.F. wrote the initial draft. J.N.P. served as the research project manager. M.A.P., J.N.F., M.M., S.K., A.S., N.N. collected and analyzed the data. All author's provided comments and approved the final draft.

Funding: The authors would like to thank the Alliance for Potato Research and Education for funding this project.

Conflicts of Interest: The author's report no conflict of interest. The funders had no role in the design of the study; collection of data; data analysis or interpretation; writing the manuscript; or decision to publish the results.

\section{References}

1. International Potato Center, Potato Facts and Figures. Available online: https://cipotato.org/crops/potato/ potato-facts-and-figures/ (accessed on 21 June 2019).

2. United States Department of Agriculture. Vegetable and Pulses Yearbook. Economic Research Service; United States Department of Agriculture: Washington, DC, USA, 2016. 
3. Birt, D.F.; Boylston, T.; Hendrich, S.; Jane, J.L.; Hollis, J.; Li, L.; McClelland, J.; Moore, S.; Phillips, G.J.; Rowling, M.; et al. Resistant starch: Promise for improving human health. Adv. Nutr. 2013, 4, 587-601. [CrossRef] [PubMed]

4. Patterson, M.A.; Maiya, M.; Stewart, M.L. Resistant starch intake in foods consumed in the United States: A Narrative Review. J. Acad. Nutr. Diet. 2019. Unpublished data.

5. Fuentes-Zaragoza, E.; Riquelme-Navarrete, M.; Sánchez-Zapata, E.; Pérez-Álvarez, J. Resistant starch as functional ingredient: A review. Food Res. Int. 2010, 43, 931-942. [CrossRef]

6. Topping, D.L.; Clifton, P.M. Short-chain fatty acids and human colonic function: Roles of resistant starch and nonstarch polysaccharides. Physiol. Rev. 2001, 81, 1031-1064. [CrossRef] [PubMed]

7. Psichas, A.; Sleeth, M.L.; Murphy, K.G.; Brooks, L.; Bewick, G.A.; Hanyaloglu, A.C.; Ghatei, M.A.; Bloom, S.R.; Frost, G. The short chain fatty acid propionate stimulates GLP-1 and PYY secretion via free fatty acid receptor 2 in rodents. Int. J. Obes. (Lond.) 2015, 39, 424-429. [CrossRef] [PubMed]

8. Tolhurst, G.; Heffron, H.; Lam, Y.S.; Parker, H.E.; Habib, A.M.; Diakogiannaki, E.; Cameron, J.; Grosse, J.; Reimann, F.; Gribble, F.M. Short-chain fatty acids stimulate glucagon-like peptide-1 secretion via the G-protein-coupled receptor FFAR2. Diabetes 2012, 61, 364-371. [CrossRef] [PubMed]

9. MacNeil, S.; Rebry, R.M.; Tetlow, I.J.; Emes, M.J.; McKeown, B.; Graham, T.E. Resistant starch intake at breakfast affects postprandial responses in type 2 diabetics and enhances the glucose-dependent insulinotropic polypeptide-insulin relationship following a second meal. Appl. Physiol. Nutr. Metab. 2013, 38, 1187-1195. [CrossRef]

10. Batterham, R.L.; Cowley, M.A.; Small, C.J.; Herzog, H.; Cohen, M.A.; Dakin, C.L.; Wren, A.M.; Brynes, A.E.; Low, M.J.; Ghatei, M.A.; et al. Gut hormone PYY(3-36) physiologically inhibits food intake. Nature 2002, 418, 650-654. [CrossRef]

11. Maziarz, M.P.; Preisendanz, S.; Juma, S.; Imrhan, V.; Prasad, C.; Vijayagopal, P. Resistant starch lowers postprandial glucose and leptin in overweight adults consuming a moderate-to-high-fat diet: A randomized-controlled trial. Nutr. J. 2017, 16, 14. [CrossRef]

12. Maki, K.C.; Pelkman, C.L.; Finocchiaro, E.T.; Kelley, K.M.; Lawless, A.L.; Schild, A.L.; Rains, T.M. Resistant starch from high-amylose maize increases insulin sensitivity in overweight and obese men. J. Nutr. 2012, 142, 717-723. [CrossRef]

13. Robertson, M.D.; Wright, J.W.; Loizon, E.; Debard, C.; Vidal, H.; Shojaee-Moradie, F.; Russell-Jones, D.; Umpleby, A.M. Insulin-sensitizing effects on muscle and adipose tissue after dietary fiber intake in men and women with metabolic syndrome. J. Clin. Endocrinol. Metab. 2012, 97, 3326-3332. [CrossRef] [PubMed]

14. Stewart, M.L.; Wilcox, M.L.; Bell, M.; Buggia, M.A.; Maki, K.C. Type-4 Resistant Starch in Substitution for Available Carbohydrate Reduces Postprandial Glycemic Response and Hunger in Acute, Randomized, Double-Blind, Controlled Study. Nutrients 2018, 10, 129. [CrossRef] [PubMed]

15. Al-Mana, N.M.; Robertson, M.D. Acute Effect of Resistant Starch on Food Intake, Appetite and Satiety in Overweight/Obese Males. Nutrients 2018, 10, 1993. [CrossRef]

16. Emilien, C.H.; Hsu, W.H.; Hollis, J.H. Effect of resistant wheat starch on subjective appetite and food intake in healthy adults. Nutrition 2017, 43, 69-74. [CrossRef] [PubMed]

17. Nayak, B.; De, J.; Berrios, J.; Tang, J. Impact of food processing on the glycemic index (GI) of potato products. Food Res. Int. 2014, 56, 35-46. [CrossRef]

18. Reader, D.; Johnson, M.L.; Hollander, P.; Franz, M. Response of resistant starch in a food bar vs. two commercially available bars in persons with type II diabetes mellitus. Diabetes 1997, 46, 254.

19. Flint, A.; Raben, A.; Blundell, J.E.; Astrup, A. Reproducibility, power and validity of visual analogue scales in assessment of appetite sensations in single test meal studies. Int. J. Obes. Relat. Metab. Disord. 2000, 24, 38-48. [CrossRef]

20. Raatz, S.K.; Idso, L.; Johnson, L.K.; Jackson, M.I.; Combs, G.F. Resistant starch analysis of commonly consumed potatoes: Content varies by cooking method and service temperature but not by variety. Food Chem. 2016, 208, 297-300. [CrossRef]

21. Zhou, J.; Martin, R.J.; Raggio, A.M.; Shen, L.; McCutcheon, K.; Keenan, M.J. The importance of GLP-1 and PYY in resistant starch's effect on body fat in mice. Mol. Nutr. Food Res. 2015, 59, 1000-1003. [CrossRef]

22. Ma, T.; Lee, C.D. Effect of Resistant Starch on Postprandial Glucose Levels in Sedentary, Abdominally Obese Persons. Diabetes 2018, 67, 792-P. [CrossRef] 
23. Ble-Castillo, J.L.; Juarez-Rojop, I.E.; Tovilla-Zarate, C.A.; Garcia-Vazquez, C.; Servin-Cruz, M.Z.; Rodriguez-Hernandez, A.; Araiza-Saldana, C.I.; Nolasco-Coleman, A.M.; Diaz-Zagoya, J.C. Acute Consumption of Resistant Starch Reduces Food Intake but Has No Effect on Appetite Ratings in Healthy Subjects. Nutrients 2017, 9, 696. [CrossRef] [PubMed]

24. Sonia, S.; Witjaksono, F.; Ridwan, R. Effect of cooling of cooked white rice on resistant starch content and glycemic response. Asia Pac. J. Clin. Nutr. 2015, 24, 620-625. [CrossRef] [PubMed]

25. Fernandes, G.; Velangi, A.; Wolever, T.M. Glycemic index of potatoes commonly consumed in North America. J. Am. Diet. Assoc. 2005, 105, 557-562. [CrossRef] [PubMed]

26. Herrmann, C.; Goke, R.; Richter, G.; Fehmann, H.C.; Arnold, R.; Goke, B. Glucagon-like peptide-1 and glucose-dependent insulin-releasing polypeptide plasma levels in response to nutrients. Digestion 1995, 56, 117-126. [CrossRef] [PubMed]

27. Inagaki, N.; Seino, Y.; Takeda, J.; Yano, H.; Yamada, Y.; Bell, G.I.; Eddy, R.L.; Fukushima, Y.; Byers, M.G.; Shows, T.B.; et al. Gastric inhibitory polypeptide: Structure and chromosomal localization of the human gene. Mol. Endocrinol. 1989, 3, 1014-1021. [CrossRef] [PubMed]

28. Shimada, M.; Mochizuki, K.; Goda, T. Dietary resistant starch reduces levels of glucose-dependent insulinotropic polypeptide mRNA along the jejunum-ileum in both normal and type 2 diabetic rats. Biosci. Biotechnol. Biochem. 2008, 72, 2206-2209. [CrossRef] [PubMed]

29. Lockyer, S.; Nugent, A. Health effects of resistant starch. Nutr. Bull. 2017, 42, 10-41. [CrossRef]

30. Goodpaster, B.H.; Sparks, L.M. Metabolic Flexibility in Health and Disease. Cell Metab. 2017, 25, 1027-1036. [CrossRef]

31. Goodpaster, B.; Kelley, D.E. Metabolic Inflexibility and Insulin Resistance in Skeletal Muscle. In Physical Activity and Type 2 Diabetes; Hawley, J., Zierath, J., Eds.; Human Kinetics Publishing: Champaign, IL, USA, 2008; pp. 59-66.

32. Ng, J.M.; Azuma, K.; Kelley, C.; Pencek, R.; Radikova, Z.; Laymon, C.; Price, J.; Goodpaster, B.H.; Kelley, D.E. PET imaging reveals distinctive roles for different regional adipose tissue depots in systemic glucose metabolism in nonobese humans. Am. J. Physiol. Endocrinol. Metab. 2012, 303, E1134-E1141. [CrossRef]

33. Wong, J.M.; de Souza, R.; Kendall, C.W.; Emam, A.; Jenkins, D.J. Colonic health: Fermentation and short chain fatty acids. J. Clin. Gastroenterol. 2006, 40, 235-243. [CrossRef]

34. Cheung, L.T.F.; Ko, G.T.C.; Chow, F.C.C.; Kong, A.P.S. Association between hedonic hunger and glycemic control in non-obese and obese patients with type 2 diabetes. J. Diabetes Investig. 2018, 9, 1135-1143. [CrossRef] [PubMed]

35. Egecioglu, E.; Skibicka, K.P.; Hansson, C.; Alvarez-Crespo, M.; Friberg, P.A.; Jerlhag, E.; Engel, J.A.; Dickson, S.L. Hedonic and incentive signals for body weight control. Rev. Endocr. Metab. Disord. 2011, 12, 141-151. [CrossRef]

36. De Roos, N.; Heijnen, M.L.; de Graaf, C.; Woestenenk, G.; Hobbel, E. Resistant starch has little effect on appetite, food intake and insulin secretion of healthy young men. Eur. J. Clin. Nutr. 1995, 49, 532-541.

37. Higgins, J.A.; Brown, I.L. Resistant starch: A promising dietary agent for the prevention/treatment of inflammatory bowel disease and bowel cancer. Curr. Opin. Gastroenterol. 2013, 29, 190-194. [CrossRef] [PubMed]

38. Anderson, G.H.; Catherine, N.L.; Woodend, D.M.; Wolever, T.M. Inverse association between the effect of carbohydrates on blood glucose and subsequent short-term food intake in young men. Am. J. Clin. Nutr. 2002, 76, 1023-1030. [CrossRef]

39. Anderson, G.H.; Cho, C.E.; Akhavan, T.; Mollard, R.C.; Luhovyy, B.L.; Finocchiaro, E.T. Relation between estimates of cornstarch digestibility by the Englyst in vitro method and glycemic response, subjective appetite, and short-term food intake in young men. Am. J. Clin. Nutr. 2010, 91, 932-939. [CrossRef] [PubMed]

40. Keogh, J.B.; Lau, C.W.; Noakes, M.; Bowen, J.; Clifton, P.M. Effects of meals with high soluble fibre, high amylose barley variant on glucose, insulin, satiety and thermic effect of food in healthy lean women. Eur. J. Clin. Nutr. 2007, 61, 597-604. [CrossRef]

(C) 2019 by the authors. Licensee MDPI, Basel, Switzerland. This article is an open access article distributed under the terms and conditions of the Creative Commons Attribution (CC BY) license (http://creativecommons.org/licenses/by/4.0/). 